\title{
SISTEM PENDUKUNG KEPUTUSAN PENENTUAN WILAYAH PROMOSI MENGGUNAKAN METODE AHP-SMART PADA UNIVERSITAS MUHAMMADIYAH PONTIANAK
}

\author{
Yulrio Brianorman*1 \\ ${ }^{1}$ Program Studi Teknik Informatika, Fakultas Teknik, Universitas Muhammadiyah Pontianak \\ Email: 1'y.brianorman@unmuhpnk.ac.id \\ *Penulis Korespondensi
}

(Naskah masuk: 03 Januari 2020, diterima untuk diterbitkan: 08 Juni 2021)

\begin{abstract}
Abstrak
Promosi merupakan upaya menawarkan produk atau jasa pada dengan tujuan menarik calon konsumen untuk membeli. Melalui promosi, produsen mengharapkan kenaikannya angka penjualan produk atau jasa yang ditawarkan. Jasa yang ditawarkan oleh sebuah perguruan tinggi swasta adalah jasa pendidikan yang dapat diukur angka penjualannya dengan jumlah kursi penerimaan mahasiswa baru. Aktivitas promosi dengan jangkauan luas memerlukan biaya yang besar sehingga perlu penentuan skala prioritas wilayah. UM Pontianak belum memiliki metode khusus untuk penentuan wilayah yang ada di Kalimantan Barat. Oleh karena itu diperlukan sistem pendukung keputusan untuk menentukan prioritas wilayah. Sistem pendukung pengambilan keputusan ini dibuat menggunakan metode AHP-SMART. Metode AHP digunakan untuk menentukan konsistensi dari skala penilaian antara kriteria sementara metode SMART untuk menyelesaikan masalah pedukung keputusan yang memiliki multikriteria. Hasil dari perhitungan AHP menunjukkan consistensi ratio $=0,05$. Dengan nilai CR di bawah 0,1 maka hasil perhitungan bobot menggunakan AHP dapat disetujui secara konsisten. Langkah selanjutnya adalah menentukan nilai prioritas dengan metode SMART. Hasil perhitungan SMART menunjukkan nilai 92,96 untuk kota Pontianak sebagai prioritas utama, disusul dengan dengan kabupaten Kuburaya, kabupaten Landak, kabupaten Sambas, kabupaten Bengkayang, kabupaten Sintang, kabupaten Ketapang, kabupaten Sanggau, kota Singkawang, kabupaten Mempawah, kabupaten Kapuas Hulu, kabupaten Sekadau, kabupaten Melawi dan kabupaten Kayong Utara.
\end{abstract}

Kata kunci: SPK, AHP, SMART, Rangking, Promosi.

\section{DECISION SUPPORT SYSTEM DETERMINATION OF PROMOTION AREA USING AHP-SMART METHOD AT MUHAMMADIYAH UNIVERSITY PONTIANAK}

\begin{abstract}
Promotion is an offering to potential customers to buy a product or service. Through promotions, producers expect an increase in sales of products or services offered. Services offered by a private tertiary institution are educational services that can be measured by sales figures with the number of new student admission seats. Delivering wide reach promotional activities require large costs so it is necessary to determine the regional priority scale. UM Pontianak does not have a specific method for determining areas in West Kalimantan yet, therefore a decision support system is needed. This decision making support system was created using the AHPSMART method. The AHP method is used to calculate the consistency of the rating scale between the criteria while the SMART method is to solve the decision support problem that has multi criteria. The results of the AHP calculation show a consistency ratio $=0.05$. With a $C R$ value below 0.1 , the weight calculation results using AHP can be consistently agreed. Furthermore, to determine the priority value, SMART method was used. The SMART results show the city of Pontianak as a top priority with the value 92.96, followed by Kuburaya district, Landak district, Sambas district, Bengkayang district, Sintang district, Ketapang district, Sanggau district, Singkawang city, Mempawah district, Kapuas Hulu district, district Sekadau, Melawi district and Kayong Utara district.
\end{abstract}

Keywords: DSS, AHP, SMART, Rank, Promotion.

\section{PENDAHULUAN}

Kegiatan promosi harus dilakukan dengan tepat sasaran dan efisien. Untuk menentukan wilayah promosi diperlukan sebuah Sistem Pendukung Keputusan dengan menggunaan suatu metode tertentu. 
Pada saat ini lembaga Infokom yang menentukan target wilayah promosi untuk Universitas Muhammadiyah Pontianak, telah menerapkan metode penentuan wilayah target promosi berdasarkan jumlah mahasiswa yang kuliah di UM Pontianak. Berdasarkan analisis dari jumlah tersebutlah lembaga Infokom menentukan area wilayah promosi untuk setiap program studi. Namun analisis dengan hanya menggunakan 1 variabel yaitu jumlah mahasiswa setiap daerah yang kuliah pada setiap program studi di UM Pontianak.

Penelitian ini memberikan alternatif analisis untuk menentukan wilayah promosi setiap program studi dengan metode AHP-SMART yang akan menjadi sebuah Sistem Pendukung Keputusan. Sistem ini diharapkan dapat memberikan analisis yang lebih akurat dikarenakan melibatkan 6 variabel. Adapun variabel yang terlibat pada analisis metode ini adalah Jumlah SMU/K, Jumlah Murid SMU/K, Pendapatan Perkapita, Jumlah Mahasiswa di UM Pontianak, Jarak Tempuh dan Biaya.

Hasil dari analisis ini diharapkan dapat memberikan prioritas kunjungan wilayah promosi untuk setiap program studi di UM Pontianak.

\section{METODE PENELITIAN}

Metodologi penelitian merupakan prinsip dasar tentang metode riset yang diterapkan dalam proses penelitian. Pada penelitian ini, ada lima proses yang akan diselesaikan yaitu Identifikasi Masalah, Studi Literatur, Survei dan Wawancara, Pengumpulan data dan Analisa dan Perhitungan.

\subsection{Identifikasi Masalah}

Pada tahapan ini dilakukan identifikasi masalah yang dihadapi oleh UM Pontianak. Permasalahan yang teridentifikasi adalah penentuan lokasi promosi penerimaan mahasiswa baru belum dilakukan dengan metode serta kriteria yang beragam. Oleh karena itu diperlukan sistem pendukung keputusan yang dapat menentukan prioritas lokasi promosi yang menggunakan metode dan kriteria yang beragam.

\subsection{Studi Literatur}

Setelah identifikasi masalah dan solusi yang diharapkan untuk menyelesaikan masalah ditentukan maka langkah selanjutnya adalah mencari literatur terkait dengan permasalahan yang dihadapi. Studi literatur dilakukan dengan membaca buku dan artikel ilmiah untuk menentukan metode apa yang digunakan. Hasil studi literatur didapat bahwa metode AHP digunakan untuk penentuan bobot kriteria dan metode SMART digunakan untuk melakukan perangkingan dari alternatif yang tersedia.

\subsection{Survei dan Wawancara}

Survei dan Wawacara dilakukan untuk menentukan kriteria apa saja yang akan digunakan pada perhitungan AHP. Setelah jenis-jenis kriteria didapat maka selanjutnya adalah penentuan kepentingan relatif antara kriteria.

\subsection{Pengumpulan Data}

Tahapan pengumpulan data dilakukan untuk menentukan nilai dari setiap kriteria dari setiap alternatif yang diberikan. Pengumpulan data ini dilakukan dengan mencari data melalui internet dan juga pengambilan data ke lapangan untuk mendapatkan data yang akurat.

\subsection{Analisa dan Perhitungan}

Pada tahapan ini dilakukan perhitungan bobot kriteria menggunakan metode AHP. Dari hasil perhitungan ini dapat analisa apakah penentuan kepentingan relatif antara kriteria sudah dapat diterima atau belum.

Jika hasil perhitungan bobot sudah dapat diterima maka tahapan selanjutnya adalah melakukan perhitungan dengan metode SMART untuk menentukan perangkingan dari setiap alternatif.

\section{TINJAUAN PUSTAKA}

Penelitian yang dilakukan oleh $\mathrm{R}$ Moh Andriawan Adikara, Muhammad Tanzil Furqon dan Achmad Arwan menggunakan metode AHP-SMART untuk menentukan varietas jagung hibrida. Pada penelitian ini metode AHP digunakan untuk menentukan bobot dari kriteria yang dipertimbangkan. Metode SMART digunakan untuk menentukan rangking dari varietas jagung (Adikara, Furqon, \& Arwan, 2018).

Metode AHP-SMART juga digunakan oleh Karmila Yusnitha, Tursina dan Muhammad Azhar Irwansyah untuk menentukan pemilihan wilayah prioritas intervensi kegiatan Keluarga Berencana. Metode AHP digunakan untuk mencari bobot kriteria dan metode SMART untuk mencari urutan prioritas wilayah (Yusnitha, Tursina, \& Irwansyah, 2019).

Penelitian lain terkait dengan sistem pengambil keputusan yang menggunakan metode AHP dan atau metode SMART diantaranya bertujuan untuk menentukan jabatan pengurus organisasi (Hayaty \& Irawan, 2018), pengukuran kualitas keamanan website e-commerce (Rahmanita, Prastiti, \& Jazari, 2018), penerimaan pegawai pada Universitas Ekasakti (Siregar, Mallisza, Yahyan, \& Hadi, 2019), pemilihan dosen terbaik (Rinaldi \& others, 2019), pemilihan dosen pembimbing skripsi berdasarkan minat mahasiswa (Abdullah \& Pangestika, 2018) dan pemilihan program studi calon mahasiswa (Pangestika \& Pratomo, 2017).

Penelitan lain terkait dengan sistem pedukung keputusan yang menggunakan metode selain AHP dan SMART diantaranya untuk pemilihan tanaman pangan pada suatu lahan berdasarkan kondisi tanah dengan metode Promethee (Adila, Regasari, \& Nurwasito, 2018), Pemilihan Taman Kanak-kanak 
dengan menggunakan metode Weighted Product (Maharani, Hermawati, Astuti, Hatta, \& Khairina, 2018), rekomendasi penerima beras sejahtera menggunaka metode Simple Additive Weighting dan Weighted Product (Berlilana \& Utomo, 2018) dan seleksi asisten dosen menggunakan kombinasi metode Profile Matching dan TOPSIS (Somya \& Wardoyo, 2019).

\section{HASIL dan PEMBAHASAN}

Hasil dari survei dan wawancara didapat kriteria pada penelitian seperti yang terlihat pada Tabel 1 . Data Kriteria.

Tabel 1. Data Kriteria

\begin{tabular}{cl}
\hline Kode & \multicolumn{1}{c}{ Kriteria } \\
\hline C1 & Jumlah SMU/K \\
C2 & Jumlah Murid SMU/K \\
C3 & Pendapatan Perkapita (ribu) \\
C4 & Jumlah Mahasiswa di UM Pontianak \\
C5 & Jarak Tempuh (km) \\
C6 & Biaya (Rp) \\
\hline
\end{tabular}

Setiap kriteria diberikan nilai kepentingan. Pemberian nilai kepentingan mengacu pada Tabel 2. Skala Saaty sumber (Kusrini \& Kom, 2007)Tabel 2. Skala Saaty.

Tabel 2. Skala Saaty

\begin{tabular}{cl}
\hline Kode & \multicolumn{1}{c}{ Kriteria } \\
\hline 1 & $\begin{array}{l}\text { Kedua Elemen sangat penting } \\
\text { Elemen yang satu sedikit lebih penting } \\
\text { dibanding elemen yang lain }\end{array}$ \\
5 & $\begin{array}{l}\text { Elemen yang satu esensial atau sanagat penting } \\
\text { disbanding elemen lainnya }\end{array}$ \\
7 & $\begin{array}{l}\text { Elemen yang satu benar-benar lebih penting } \\
\text { dari yang lain }\end{array}$ \\
9 & $\begin{array}{l}\text { Elemen yang satu mutlak lebih penting } \\
\text { Nilai tengah diantara dua penilaian berurutan } \\
\text { Jika aktivitas i mendapat satu angka } \\
\text { Kebalikan }\end{array}$ \\
& $\begin{array}{l}\text { dibandingkan dengan aktivitas j, maka j } \\
\text { memiliki nilai kebalikannya dibandingkan } \\
\text { dengan i. }\end{array}$ \\
\hline
\end{tabular}

Jika terdapat $n$ elemen maka akan diperoleh matriks perbandingan berpasangan pada persamaan (1) berdimensi $n \times n$, dan banyaknya penilaian yang diperlukan adalah sebanyak $n(n-1) / 2$.

$A=\left[\begin{array}{ccc}a_{11} & \cdots & a_{1 n} \\ \vdots & \ddots & \vdots \\ a_{n 1} & \cdots & a_{n n}\end{array}\right]$

Berdasarkan hasil survei dan perbandingan antar kriteria maka didapat matriks perbandingan berpasangan seperti terlihat pada Tabel 3. Matriks Perbandingan Berpasangan.

Tabel 3. Matriks Perbandingan Berpasangan

\begin{tabular}{c|cccccc}
\hline \multicolumn{1}{c}{ C1 } & C2 & C3 & C4 & C5 & C6 \\
\hline C1 & 1,00 & 3,00 & 3,00 & 3,00 & 5,00 & 7,00 \\
C2 & 0,33 & 1,00 & 3,00 & 3,00 & 5,00 & 7,00 \\
C3 & 0,33 & 0,33 & 1,00 & 3,00 & 3,00 & 5,00 \\
C4 & 0,33 & 0,33 & 0,33 & 1,00 & 3,00 & 3,00 \\
C5 & 0,20 & 0,20 & 0,33 & 0,33 & 1,00 & 2,00 \\
C6 & 0,14 & 0,14 & 0,20 & 0,33 & 0,50 & 1,00 \\
\hline Total & $\mathbf{2 , 3 4}$ & $\mathbf{5 , 0 1}$ & $\mathbf{7 , 8 7}$ & $\mathbf{1 0 , 6 7}$ & $\mathbf{1 7 , 5 0}$ & $\mathbf{2 5 , 0 0}$ \\
\hline
\end{tabular}

Melakukan normalisasi matriks dengan menggunakan persamaan (2).

$W=\left[\begin{array}{cccc}\frac{a_{11}}{\sum_{i=1}^{n} a_{i 1}} & \frac{a_{12}}{\sum_{i=1}^{n} a_{i 2}} & \cdots & \frac{a_{1 n}}{\sum_{i=1}^{n} a_{i n}} \\ \frac{a_{21}}{\sum_{i=1}^{n} a_{i 1}} & \frac{a_{12}}{\sum_{i=1}^{n} a_{i 2}} & \ddots & \frac{a_{2 n}}{\sum_{i=1}^{n} a_{i n}} \\ \vdots & \vdots & \ddots & \vdots \\ \frac{a_{21}}{\sum_{i=1}^{n} a_{n 1}} & \frac{a_{n 2}}{\sum_{i=1}^{n} a_{n 2}} & \cdots & \frac{a_{2 n}}{\sum_{i=1}^{n} a_{i n}}\end{array}\right]$

Hasil perhitungan akan menghasilkan matriks normalisasi

Tabel 4. Matriks Normalisasi

\begin{tabular}{c|cccccc}
\hline \multicolumn{1}{c}{ C1 } & C2 & C3 & C4 & C5 & C6 \\
\hline C1 & 0,43 & 0,60 & 0,38 & 0,28 & 0,29 & 0,28 \\
C2 & 0,14 & 0,20 & 0,38 & 0,28 & 0,29 & 0,28 \\
C3 & 0,14 & 0,07 & 0,13 & 0,28 & 0,17 & 0,20 \\
C4 & 0,14 & 0,07 & 0,04 & 0,09 & 0,17 & 0,12 \\
C5 & 0,09 & 0,04 & 0,04 & 0,03 & 0,06 & 0,08 \\
C6 & 0,06 & 0,03 & 0,03 & 0,03 & 0,03 & 0,04 \\
\hline Total & $\mathbf{1 , 0 0}$ & $\mathbf{1 , 0 0}$ & $\mathbf{1 , 0 0}$ & $\mathbf{1 , 0 0}$ & $\mathbf{1 , 0 0}$ & $\mathbf{1 , 0 0}$ \\
\hline
\end{tabular}

Menghitung rata-rata matriks normalisasi yang hasilnya akan menjadi bobot itu setiap kriteria dengan menggunakan persamaaan (3).

$A R_{i}=\frac{\sum_{i=1}^{n} W_{1 n}}{n}$

$A R_{1}=\frac{0,43+0,60+0,38+0,28+0,29+0,28}{6}=0,38$

Perhitungan pada persamaan (444) dilakukan pada setiap baris matriks normalisasi maka akan didapat hasil seperti pada Tabel 5. Bobot Kriteria.

Tabel 5. Bobot Kriteria

\begin{tabular}{cccccc}
\hline $\boldsymbol{A R}_{\mathbf{1}}$ & $\boldsymbol{A R}_{\mathbf{2}}$ & $\boldsymbol{A R}_{\mathbf{3}}$ & $\boldsymbol{A R}_{\mathbf{4}}$ & $\boldsymbol{A R}_{\mathbf{5}}$ & $\boldsymbol{A R}_{\mathbf{6}}$ \\
\hline 0,38 & 0,26 & 0,16 & 0,11 & 0,06 & 0,04 \\
\hline
\end{tabular}

Langkah selanjutnya adalah melakukan perkalian matriks Tabel 1. Data Kriteria dengan Error! Reference source not found. seperti pada persamaan (5).

$B=\left[\begin{array}{ccc}a_{11} & \cdots & a_{1 n} \\ \vdots & \ddots & \vdots \\ a_{n 1} & \cdots & a_{n n}\end{array}\right]\left[\begin{array}{c}A R_{1} \\ \vdots \\ A R_{n}\end{array}\right]$

Hasil perhitungan akan diperoleh seperti terlihat pada

Tabel 6. Hasil Perkalian.

Tabel 6. Hasil Perkalian

\begin{tabular}{rrrrrc}
\hline $\boldsymbol{B}_{\mathbf{1}}$ & $\boldsymbol{B}_{\mathbf{2}}$ & $\boldsymbol{B}_{\mathbf{3}}$ & $\boldsymbol{B}_{\mathbf{4}}$ & $\boldsymbol{B}_{\mathbf{5}}$ & $\boldsymbol{B}_{\mathbf{6}}$ \\
\hline 2,50 & 1,73 & 1,04 & 0,65 & 0,35 & 0,22 \\
\hline
\end{tabular}

Untuk menghitung $\lambda$ Max dilakukan pembagian antara 
Tabel 6. Hasil Perkalian dengan Tabel 5. Bobot Kriteria menghasilkan Tabel 7. Hasil Pembagian $\left(\frac{A R_{n}}{B_{n}}\right.$ ) .

Tabel 7. Hasil Pembagian $\left(\frac{A R_{n}}{B_{n}}\right)$

\begin{tabular}{cccccc}
\hline$\lambda_{1}$ & $\lambda_{2}$ & $\lambda_{3}$ & $\lambda_{4}$ & $\lambda_{5}$ & $\lambda_{6}$ \\
\hline 6,67 & 6,61 & 6,33 & 6,12 & 6,17 & 6,24 \\
\hline
\end{tabular}

Perhitungan selanjutnya adalah menghitung $\lambda$ Max dengan menggunakan persamaan (6) dan menghasilkan $\lambda \operatorname{Max}=6,35$.

$\lambda \operatorname{Max}=\frac{\sum_{n=1}^{n} \frac{A R_{n}}{B_{n}}}{n}=\frac{38,12}{6}=6,35$

Untuk menghitung Consistensi Index (CI) menggunakan persamaan (7) dan menghasilkan $C I=$ 0,07

$C I=\frac{\lambda M a x-1}{n-1}=\frac{6,35-6}{5}=0,07$

Untuk menghitung Consistensi Ratio (CR) menggunakan persamaan (8) dan menghasilkan $C R=0,05$.

$C R=\frac{C I}{I R}=\frac{0,07}{1,32}=0,05$

Adapun Index Random (IR) merujuk pada Tabel 8. Index Random untuk nilai $\mathrm{n}=$ jumlah kriteria. Pada penelitian ini jumlah kriteria $n=6$ sehingga nilai $I R=1,32$.

Tabel 8. Index Random

\begin{tabular}{c|cccccccc}
\hline $\mathbf{n}$ & $\mathbf{1}$ & $\mathbf{2}$ & $\mathbf{3}$ & $\mathbf{4}$ & $\mathbf{5}$ & $\mathbf{6}$ & $\mathbf{7}$ & $\mathbf{8}$ \\
\hline $\mathbf{I R}$ & 0 & 0 & 0,58 & 0,90 & 1,12 & 1,32 & 1,41 & 1,49 \\
\hline
\end{tabular}

Jika nilai Consistensi Rasio $<0,01$ maka perbandingan matriks yang dilakukan dapat diterima. Sehingga proses survei untuk proses perbandingan antar kriteria tidak perlu diulang.

Setelah mendapatkan hasil bobot kriteria yang terlihat pada Tabel 5. Bobot Kriteria, maka akan dilakukan perhitungan pada alternatif. Adapun alternatif yang dimiliki pada penelitian ini terlihat pada

Tabel 9. Data Alternatif.

Tabel 9. Data Alternatif

\begin{tabular}{clcl}
\hline Kode & \multicolumn{1}{c}{ Alternatif } & Kode & \multicolumn{1}{c}{ Alternatif } \\
\hline A1 & Sambas & A8 & Kapuas Hulu \\
A2 & Bengkayang & A9 & Sekadau \\
A3 & Landak & A10 & Melawi \\
A4 & Mempawah & A11 & Kayong Utara \\
A5 & Sanggau & A12 & Kuburaya \\
A6 & Ketapang & A13 & Kota Pontianak \\
A7 & Sintang & A14 & Kota Singkawang \\
\hline
\end{tabular}

Setiap alternatif diberikan nilai untuk setiap alternatif seperti yang terlihat pada Tabel 10. Nilai Alternatif Setiap Kriteria.
Langkah selanjutnya adalah menghitung nilai utiliti. Perhitungan ini bergantung pada sifat dari kriteria tersebut.

Tabel 10. Nilai Alternatif Setiap Kriteria

\begin{tabular}{ccccccc}
\hline Kode & C1 & C2 & C3 & C4 & C5 & C6 \\
\hline A1 & 37 & 11202 & 9774 & 416 & 225 & 200.000 \\
A2 & 30 & 7493 & 9072 & 176 & 153 & 150.000 \\
A3 & 45 & 12452 & 7183 & 271 & 144 & 200.000 \\
A4 & 12 & 5387 & 7779 & 357 & 67 & 80.000 \\
\hline A5 & 28 & 8972 & 8126 & 482 & 267 & 180.000 \\
A6 & 34 & 10462 & 8988 & 462 & 354 & 400.000 \\
A7 & 37 & 9627 & 8624 & 286 & 395 & 250.000 \\
A8 & 31 & 7741 & 7074 & 269 & 673 & 400.000 \\
A9 & 21 & 5116 & 7374 & 178 & 315 & 200.000 \\
A10 & 21 & 5223 & 8202 & 571 & 493 & 170.000 \\
A11 & 13 & 3890 & 7552 & 316 & 315 & 350.000 \\
A12 & 60 & 12002 & 8532 & 363 & 51 & 40.000 \\
A13 & 51 & 19108 & 14322 & 1068 & 5 & 20.000 \\
A14 & 17 & 4977 & 11514 & 119 & 145 & 150.000 \\
\hline Sifat & B & B & B & B & C & C \\
\hline Max & 60 & 19108 & 14322 & 1068 & 673 & 400.000 \\
\hline Min & 12 & 3890 & 7074 & 119 & 5 & 20.000 \\
\hline
\end{tabular}

Untuk kriteria yang makin besar nilainya makin baik maka memiliki sifat Benefit. Adapun sebalikanya disebut sifat Cost. Sifat benefit dihitung dengan persamaan (9) sedangkan sifat cost menggunakan persamaan (10).

$$
\begin{aligned}
& u_{i}\left(a_{i}\right)=\frac{C_{i}-C_{\min }}{C_{\max }-C_{\min }} \\
& u_{i}\left(a_{i}\right)=\frac{C_{\max }-C_{i}}{C_{\max }-C_{\min }}
\end{aligned}
$$

Hasil dari perhitungan didapat

Tabel 11. Nilai Utiliti

\begin{tabular}{ccccccc}
\hline Kode & C1 & C2 & C3 & C4 & C5 & C6 \\
\hline $\mathbf{A 1}$ & 52,08 & 48,05 & 37,25 & 31,30 & 67,07 & 52,63 \\
$\mathbf{A 2}$ & 37,50 & 23,68 & 27,57 & 6,01 & 77,84 & 65,79 \\
$\mathbf{A 3}$ & 68,75 & 56,26 & 1,50 & 16,02 & 79.19 & 52,63 \\
$\mathbf{A 4}$ & 0 & 9,84 & 9,73 & 25,08 & 90,72 & 84,21 \\
$\mathbf{A 5}$ & 33.33 & 33,39 & 14,51 & 38,25 & 60,78 & 57,89 \\
$\mathbf{A 6}$ & 45.83 & 43,19 & 26,41 & 36,14 & 47,75 & 0,00 \\
$\mathbf{A 7}$ & 52.08 & 37,70 & 21,39 & 17,60 & 41,62 & 39,47 \\
$\mathbf{A 8}$ & 39,58 & 24,31 & 0 & 15,81 & 0 & 0 \\
$\mathbf{A 9}$ & 18,75 & 8,06 & 3,48 & 6,22 & 53,59 & 52,63 \\
$\mathbf{A 1 0}$ & 18,75 & 8,76 & 15,56 & 47,63 & 26,95 & 60,53 \\
$\mathbf{A 1 1}$ & 2,08 & 0 & 6,59 & 20,76 & 53,59 & 13,16 \\
$\mathbf{A 1 2}$ & 100 & 53,31 & 20,12 & 25,71 & 93,11 & 94,74 \\
$\mathbf{A 1 3}$ & 81,25 & 100 & 100 & 100 & 100 & 100 \\
$\mathbf{A 1 4}$ & 10,42 & 7,14 & 7,14 & 0,00 & 79,04 & 65,79 \\
\hline
\end{tabular}

Untuk mendapat peringkat prioritas dari alternatif maka setiap kriteria dari alternatif dikalikan dengan bobot pada Tabel 5. Bobot Kriteria sesuai dengan persamaan 11 .

$u\left(a_{i}\right)=\sum_{i=1}^{n} u_{i} A R_{i}$

Hasil perhitungan didapat seperti pada Tabel 12. Hasil Perangkingan. 
Tabel 12. Hasil Perangkingan

\begin{tabular}{llc}
\hline Kode & \multicolumn{1}{c}{ Alternatif } & Nilai Total \\
\hline A1 & Sambas & 47,24 \\
A2 & Bengkayang & 32,18 \\
A3 & Landak & 48,82 \\
\hline A4 & Mempawah & 14,93 \\
A5 & Sanggau & 33,19 \\
A6 & Ketapang & 39,38 \\
A7 & Sintang & 38,57 \\
A8 & Kapuas Hulu & 23,17 \\
A9 & Sekadau & 15,27 \\
A10 & Melawi & 20,63 \\
A11 & Kayong Utara & 7,54 \\
A12 & Kuburaya & 66,16 \\
A13 & Kota Pontianak & 92,96 \\
A14 & Kota Singkawang & 22,66 \\
\hline
\end{tabular}

Jika hasil perangkingan diurutkan maka akan terlihat seperti pada

Tabel 13. Urutan Prioritas Kabupaten/Kota

\begin{tabular}{clc}
\hline No & \multicolumn{1}{c}{ Kabupaten Kota } & Nilai \\
\hline $\mathbf{1}$ & Kota Pontianak & 92,96 \\
$\mathbf{2}$ & Kuburaya & 74,04 \\
$\mathbf{3}$ & Landak & 55,07 \\
$\mathbf{4}$ & Sambas & 49,22 \\
$\mathbf{5}$ & Bengkayang & 39,49 \\
$\mathbf{6}$ & Sintang & 39,35 \\
$\mathbf{7}$ & Ketapang & 38,20 \\
$\mathbf{8}$ & Sanggau & 34,43 \\
$\mathbf{9}$ & Kota Singkawang & 30,61 \\
$\mathbf{1 0}$ & Mempawah & 22,88 \\
$\mathbf{1 1}$ & Kapuas Hulu & 21,49 \\
$\mathbf{1 2}$ & Sekadau & 17,26 \\
$\mathbf{1 3}$ & Melawi & 15,58 \\
$\mathbf{1 4}$ & Kayong Utara & 7,99 \\
\hline
\end{tabular}

\section{KESIMPULAN}

Adapun kesimpulan yang didapat dari penelitian Sisstem Pendukung Keputusan Penentuan Wilayah Promosi Menggunakan Metode Ahp-Smart pada Universitas Muhammadiyah Pontianak ini adalah

1. Penentuan bobot dihitung dengan metode AHP sedangkan metode SMART digunakan untuk menetukan perangkingan alternatif telah berhasil dilakukan.

2. Sistem Pendukung Keputusan pemilihan wilayah promosi Penerimaan Mahasiswa Baru telah menentukan kota Pontianak sebagai tujuan promosi utama diikutin dengan Kubu Raya, Landak, Sambas, Bengkayang, Sintang, Ketapang, Sanggau, Kota Singkawang, Mempawah, Kapuas Hulu, Sekadau, Melawi dan Kayong Utara.

3. Penelitian ini telah dapat menyelesaikan permasalahan yang dihadapi UM Pontianak dalam menentukan prioritas promosi Penerimaan Mahasiswa Baru.

\section{DAFTAR PUSTAKA}

ABDULlAH, A., \& PANGESTIKA, M. W. 2018. Perancangan Sistem Pendukung Keputusan dalam Pemilihan Dosen Pembimbing Skripsi Berdasarkan Minat Mahasiswa dengan Metode
AHP (Analytical Hierarchy Process) di Universitas Muhammadiyah Pontianak. Jurnal Edukasi Dan Penelitian Informatika (JEPIN), 4(2),

184. https://doi.org/10.26418/jp.v4i2.27651

ADIKARA, R. M. A., FURQON, M. T., \& ARWAN, A. 2018. Sistem Pendukung Keputusan Pemilihan Varietas Unggul Jagung Hibrida Menggunakan Metode AHP-SMART. Jurnal Pengembangan Teknologi Informasi Dan Ilmu Komputer (J-PTIIK) Universitas Brawijaya, 2(10), 3373-3380.

ADILA, W. N., REGASARI, R., \& NURWASITO, H. 2018. Sistem Pendukung Keputusan (SPK) Pemilihan Tanaman Pangan Pada Suatu Lahan Berdasarkan Kondisi Tanah Dengan Metode Promethee. Jurnal Pengembangan Teknologi Informasi Dan Ilmu Komputer E-ISSN, 2548, 964X.

BERLILANA, F. D. P., \& UTOMO, F. S. 2018. Implementasi Simple Additive Weighting dan Weighted Product pada Sistem Pendukung Keputusan untuk Rekomendasi Penerima Beras Sejahtera. Jurnal Teknologi Informasi Dan Ilmu Komputer (JTIIK), 5(4).

HAYATY, M., \& IRAWAN, R. F. 2018. Perancangan Sistem Penunjang Keputusan untuk Menentukan Jabatan Pengurus Organisasi Menggunakan Kombinasi Algoritma Simple Multi Attribute Rating Technique (SMART) dan Forward Chaining. Khazanah Informatika: Jurnal Ilmu Komputer Dan Informatika, 4(2), 104. https://doi.org/10.23917/khif.v4i2.7034

KUSRINI, M. K., \& KOM, M. 2007. Konsep dan Aplikasi Sistem Pendukung Keputusan.

MAHARANI, S., HERMAWATI, S., ASTUTI, I. F., HATTA, H. R., \& KHAIRINA, D. M. 2018. Pemilihan Taman Kanak-kanak Menggunakan Metode Weighted Product di Kecamatan Sungai Kunjang Samarinda. Jurnal Teknologi Informasi Dan Ilmu Komputer (JTIIK), 5(4).

PANGESTIKA, M. W., \& PRATOMO, Y. Q. 2017. Analytic Hierarchy Process Untuk Pemilihan Program Studi Calon Mahasiswa. CYBERNETICS, 1(01), 22-29.

RAHMANITA, E., PRASTITI, N., \& JAZARI, I. 2018. Penggunaan Metode AHP dan FAHP dalam Pengukuran Kualitas Keamanan Website E-Commerce. Jurnal Teknologi Informasi Dan Ilmu Komputer, 5(3), 371. https://doi.org/10.25126/jtiik.201853816

RINALDI, S., dkk. 2019. Implementasi Metode Analytical Hierarchy Process dan Simple Additive Weighting untuk Pemilihan Dosen Terbaik Studi Kasus STMIK Atma Luhur. Jurnal Teknologi Informasi Dan Ilmu Komputer, 6(6), 655-664. 
444 Jurnal Teknologi Informasi dan Ilmu Komputer (JTIIK), Vol. 8, No. 3, Juni 2021, hlm. 439-444

SIREGAR, M. I. A., MALLISZA, D., YAHYAN, W., \& HADI, H. S. 2019. Sistem Pendukung Keputusan Penerimaan Pegawai pada Universitas Ekasakti Menggunakan Metode AHP. Indonesian Journal of Computer Science, 8(1), 45-54. https://doi.org/10.33022/ijcs.v8i1.157

SOMYA, R., \& WARDOYO, R. 2019. Perancangan Sistem Pendukung Keputusan Seleksi Asisten Dosen Menggunakan Kombinasi Metode Profile Matching dan TOPSIS Berbasis Web Service. Khazanah Informatika: Jurnal Ilmu Komputer Dan Informatika, 5(1), 44-50.

YUSNITHA, K., TURSINA, T., \& IRWANSYAH, M. A. 2019. Sistem Pendukung Keputusan Pemilihan Wilayah Prioritas Intervensi Kegiatan Keluarga Berencana dengan Metode AHP-SMART. Jurnal Edukasi Dan Penelitian Informatika (JEPIN), 5(1), 99. https://doi.org/10.26418/jp.v5i1.31338 